\title{
Characteristics of Patients With Aneurysmal Subarachnoid Hemorrhage and Risk Factors Related to Dysphagia
}

\author{
Seung Hwa Rhie, $\mathrm{MD}^{1}$, Ji Won Choi, $\mathrm{MD}^{1}$, Se Jeong Jeon, $\mathrm{MD}^{2}$, \\ Sung Don Kang, $\mathrm{MD}^{3}$, Min Cheol Joo, $\mathrm{MD}^{1}$, Min Su Kim, $\mathrm{MD}^{1}$ \\ ${ }^{1}$ Department of Rehabilitation Medicine, Wonkwang University School of Medicine \& Hospital, Iksan; \\ Departments of ${ }^{2}$ Radiology, ${ }^{3}$ Neurosurgery, Wonkwang University School of Medicine, Iksan, Korea
}

\begin{abstract}
Objective To investigate the characteristics and risk factors of dysphagia with the Videofluoroscopic Dysphagia Scale (VDS) using a videofluoroscopic swallowing study (VFSS) in patients with ruptured aneurysmal subarachnoid hemorrhage (aSAH).

Methods Data of 64 patients presenting with first-ever ruptured aSAH were analyzed. Characteristics of dysphagia were evaluated using VFSS and all subjects were divided into a high $(>47)$ and low risk group $(\leq 47)$ by the VDS score. Clinical and functional parameters were assessed by medical records including demographics, hypertension and diabetes mellitus (DM), the Glasgow Coma Scale (GCS), the Hunt and Hess scale, endotracheal intubation, acute management modalities, as well as Korean version of the Mini-Mental Status Examination (K-MMSE) and Korean version of Modified Barthel Index (K-MBI). Radiologic factors identified the amount of hemorrhage, ventricular rupture, and aneurysmal location.

Results About a half of the subjects showed oral phase abnormalities and the oral transit time was delayed in $46.8 \%$ of the patients. The pharyngeal transit time was also prolonged in $39.0 \%$ of the subjects and the proportion of penetration and aspiration observed was $46.8 \%$. The parameters-GCS score $(\mathrm{p}=0.048)$, hemorrhagic volume $(\mathrm{p}=0.028)$, presence of intraventricular hemorrhage $(\mathrm{p}=0.038)$, and K-MMSE $(\mathrm{p}=0.007)$-were predisposing factors for dysphagia in patients with aSAH.

Conclusion Abnormalities in the oral phase were more prominent in patients with aSAH than in those with other types of stroke. The risk factors associated with dysphagia persisting over 6 months after stroke onset were the initial GCS, hemorrhage volume, presence of intraventricular hemorrhage, and cognitive status as measured by the K-MMSE.
\end{abstract}

Keywords Deglutition disorders, Deglutition, Fluoroscopy, Subarachnoid hemorrhage

Received July 18, 2016; Accepted September 13, 2016

Corresponding author: Min Su Kim

Department of Rehabilitation Medicine, Wonkwang University School of Medicine \& Hospital, 895 Muwang-ro, Iksan 54538, Korea. Tel: +82-63-8591610, Fax: +82-63-843-1385, E-mail: helmaine@naver.com

ORCID: Seung Hwa Rhie (http://orcid.org/0000-0003-0663-8331); Jiwon Choi (http://orcid.org/0000-0002-5339-4854); Se Jeong Jeon (http://orcid. org/0000-0002-1134-2757); Sung Don Kang (http://orcid.org/0000-0002-3965-1674); Min Cheol Joo (http://orcid.org/0000-0003-2778-4194); Min Su Kim (http://orcid.org/0000-0001-9954-1445).

(c) This is an open-access article distributed under the terms of the Creative Commons Attribution Non-Commercial License (http://creativecommons.org/ licenses/by-nc/4.0) which permits unrestricted noncommercial use, distribution, and reproduction in any medium, provided the original work is properly cited. Copyright ( 2016 by Korean Academy of Rehabilitation Medicine 


\section{INTRODUCTION}

Aneurysmal subarachnoid hemorrhage (aSAH) is a lifethreatening type of stroke caused by bleeding into the arachnoid space surrounding the brain. The incidence ranges from 2 to 16 per 100,000 people in a recent review of population-based studies [1].

Although case fatality rates have decreased significantly over the past three decades as a result of improved diagnostic techniques and treatment modalities, aSAH is a significant cause of mortality, in particular since at least one quarter die [2]. In addition, more than half of the survivors are left with persistent neurological deficits including cognitive and functional impairments, behavioral change, depression, as well as swallowing difficulties.

Specifically, dysphagia is a morbidity of great concern in aSAH as well as other types of stroke, because it increases the risk for pneumonia up to 11-fold [3] and malnutrition, which crucially impedes functional recovery $[4,5]$. Dysphagia is a common sequela found in as much as half of all individuals with a recent stroke [6], yet there are few reports addressing dysphagia in aSAH. To the best of our knowledge, only one retrospective study thus far has reported that $17.9 \%(n=7)$ of the survivors showed dysphagia in primary aSAH [7], but characteristics and risk factors of dysphagia were not further analyzed in this investigation.

Therefore, we investigated the characteristics and risk factors of severe dysphagia using the Videofluoroscopic Dysphagia Scale (VDS) via a videofluoroscopic swallowing study (VFSS), which is the standard instrument for evaluating dysphagia and assessing management of patients with aSAH.

\section{MATERIALS AND METHODS}

\section{Subjects}

We analyzed medical records of patients in our stroke database at Wonkwang University Hospital. Patients presenting with a primary ruptured aSAH between January 2011 and December 2015 were included. All of them underwent computed tomography (CT) of the brain and a CT angiography within 24 hours of initial hemorrhage, if they were diagnosed with aSAH, and then examined by neurosurgeons and a neuroradiologist. Physiatrists used functional scales at the time of the VFSS. Exclusion criteria were as follows: (1) patients with co-existing intracerebral hemorrhage (ICH) or cerebral infarct; (2) preexisting dysphagia; (3) past medical history of diseases that affect swallowing function including stroke, Parkinson disease, multiple sclerosis, motor neuron disease, and dementia. This study was approved by the Institutional Review Board of Wonkwang University Hospital (No. WKUH 201512-HRE-118).

\section{Dysphagia assessment}

The swallowing function was evaluated by VDS, using VFSS according to Logemann's protocol within 2 months of onset [8]. In sequential order, each patient ingested (1) $2 \mathrm{~mL}$ of $35 \%$ diluted barium, (2) pudding coated with barium, (3) curd-type yogurt and barium, (4) rice gruel coated with barium, and (5) half a cookie coated with barium during the VFSS. Oral, pharyngeal, and esophageal stages of swallowing physiology were simultaneously evaluated both laterally and anteroposteriorly. All test procedures were recorded on digital DVDs.

The VDS, which is one of the most popular evaluation tools for swallowing function in stroke patients, was analyzed and calculated by data obtained from the VFSS by a physiatrist. It can be utilized as a diagnostic tool, but also employed for prognoses of dysphagia patients during six months after stroke onset, as well as an objective and quantifiable predictor of recovery of the swallowing function after stroke $[9,10]$. The VDS consists of 14 items to estimate swallowing characteristics in both the oral and pharyngeal phases and it can be quantified as a score that describes the degree of impairment, ranging from 0 to 100 .

The VDS items reflect oral (lip closure, bolus formation, mastication, apraxia, premature bolus loss, oral transit time) and pharyngeal (pharyngeal triggering, vallecular and pyriform sinus residues, laryngeal elevation, epiglottic closure, pharyngeal coating, pharyngeal transit time, aspiration) functions that can be observed by the VFSS [11]. Severity of swallowing apraxia was categorized for different stages according to Daniels' criteria [12]: normal (when instructed to swallow, the subject has no difficulty initiating and organizing lingual movements for bolus propulsion), mild (there is a slight delay in initiation and/ or has oral transfer discoordination for bolus propulsion when instructed to swallow), moderate (initiation is markedly delayed and/or oral transfer discoordination 
for bolus propulsion exists) and severe (the subject cannot initiate and organize lingual movements).

\section{Risk factors}

All subjects were divided into two groups according to their VDS scores to investigate dysphagia risk factors over 6 months after stroke onset as associated with aSAH. Patients who gained more than 47 points were assigned to the high-risk group and the others were classified as at low-risk for dysphagia over 6 months after stroke onset, based on a study by Han et al. [9] where the high-risk stroke patients with dysphagia displayed a poor prognosis. The cutoff value of 47 measured during the subacute period showed high sensitivity (0.91) and specificity (0.92) and aspiration was used as the standard for judging a dysphagia poststroke [9].

The clinical and functional parameters that may affect dysphagia in patients with aSAH were investigated. Clinical assessments comprised the following: demographics, past medical history of hypertension and diabetes mellitus (DM), the initial Glasgow Coma Scale (GCS) as well as the Hunt and Hess scale in the emergency room, history of endotracheal intubation during acute management, and modalities of treatment including aneurysmal clipping or coiling and conservative therapy. Functional states, including the Korean version of the Mini-Mental Status Examination (K-MMSE) and Korean version of the Modified Barthel Index (K-MBI), were also administered at the time of the VFSS.

Each brain CT scan was reviewed by a neuroradiologist to identify factors including the amount of subarachnoid blood, the presence of ventricular rupture, and aneurysmal location. The volume of subarachnoid hemorrhage was quantified by the method of Hijdra et al. [13]: 10 basal cisterns or fissures including a frontal interhemispheric fissure, 2 lateral parts of the sylvian fissure, 2 basal parts of the sylvian fissure, 2 suprasellar cisterns, 2 ambient cisterns, and a quadrigeminal cistern were classified separately ( 0 , no blood; 1 , small amount of blood; 2 , moderate amount of blood; 3 , completely filled with blood). These scores were added to yield a Hijdra Sum Score (HSS) ranging from 0 to 30 .

The presence of intraventricular hemorrhage (IVH) was verified in the bilateral, third, and fourth ventricles. The aneurysm's location was classified as anterior communicating (A-com), posterior communicating (P-com), middle cerebral (MCA), internal carotid (ICA), basilar, pericallosal, and other arteries.

\section{Statistical analysis}

Baseline characteristics of the study groups were presented as numbers and percentages for categorical variables, and as mean and standard deviation for continuous variables. The chi-square test was used to compare each VDS parameter in the high- and low-risk groups. Group comparisons conducted by the chi-square test and Fisher exact test for qualitative variables, as well as the independent t-test for quantitative variables. The Kolmogorov-Smirnov test evaluated data distributions before group comparisons were calculated for quantitative variables.

The associated factors expected to be persisting dysphagia over 6 months after stroke onset were evaluated using a binary logistic regression model. All relevant covariates with a $p$-value of $<0.05$ were entered in the multivariate model following univariate analysis. Results were presented as odds ratios with $95 \%$ confidence intervals. Statistical analysis was performed with the SPSS ver. 19.4 software package (SPSS Inc., Chicago, IL, USA), and the significance level was set at $\mathrm{p}=0.05$.

\section{RESULTS}

A total of 64 patients were eligible for this study, because 2 patients were excluded because they lacked VFSS data. Baseline clinical, radiologic, and functional characteristics of the eligible patients are shown in Table 1 . The average time period from aSAH onset to VFSS performance was $33.7 \pm 11.1$ days.

Frequencies of salient findings on VDS are displayed in Table 2. Approximately half of the subjects showed oral phase abnormalities in bolus formation, mastication, apraxia, tongue-to-palate contact, and premature bolus loss. Oral transit time was delayed in $46.8 \%$ of the patients. Residues in the vallecular space and/or pyriform sinus were found in half of the patients and the pharyngeal transit time was also prolonged in $39.0 \%$ of the sample. The proportion of penetration and aspiration, regardless of food consistencies, was $46.8 \%$. The mean VDS score of all patients was $23.5 \pm 25.5$. Statistically significant differences were not observed between the two groups for each VDS parameter. 
Table 1. Baseline of the patient's characteristics $(n=64)$

\begin{tabular}{|c|c|}
\hline Characteristic & Value \\
\hline \multicolumn{2}{|l|}{ Clinical factors } \\
\hline Age (yr) & $54.6 \pm 17.7$ \\
\hline \multicolumn{2}{|l|}{ Sex } \\
\hline Male & $25(39.1)$ \\
\hline Female & $39(60.9)$ \\
\hline Hypertension & $48(75.0)$ \\
\hline $\mathrm{DM}$ & $13(20.3)$ \\
\hline Initial GCS & $10.1 \pm 4.5$ \\
\hline Endotracheal tube & $6(9.3)$ \\
\hline \multicolumn{2}{|l|}{ Treatment modality } \\
\hline Clipping & $54(84.3)$ \\
\hline Coiling & $8(12.5)$ \\
\hline Conservative management & $2(3.2)$ \\
\hline \multicolumn{2}{|l|}{ Hunt and Hess scale } \\
\hline Grade 1 & $0(0)$ \\
\hline Grade 2 & $11(17.2)$ \\
\hline Grade 3 & $13(20.3)$ \\
\hline Grade 4 & $37(57.8)$ \\
\hline Grade 5 & $3(4.7)$ \\
\hline \multicolumn{2}{|l|}{ Radiologic factors } \\
\hline Hijdra score & $20.0 \pm 7.5$ \\
\hline Presence of ventricular rupture & $29(45.3)$ \\
\hline \multicolumn{2}{|l|}{ Aneurysmal location } \\
\hline A-com & $18(28.1)$ \\
\hline P-com & $13(20.3)$ \\
\hline MCA & $13(20.3)$ \\
\hline Pericallosal & $8(12.5)$ \\
\hline ICA bifurcation & $5(7.8)$ \\
\hline Basilar tip & $3(4.7)$ \\
\hline Others & $4(6.3)$ \\
\hline \multicolumn{2}{|l|}{ Functional factors } \\
\hline K-MMSE & $12.9 \pm 9.3$ \\
\hline K-MBI & $29.9 \pm 25.8$ \\
\hline Tube feeding & $30(46.9)$ \\
\hline VFSS time from the onset (day) & $33.7 \pm 11.1$ \\
\hline
\end{tabular}

Values are presented as mean \pm standard deviation or number (\%).

DM, diabetes mellitus; GCS, Glasgow Coma Scale; Acom, anterior communicating artery; P-com, posterior communicating artery; MCA, middle cerebral artery; ICA, internal carotid artery; K-MMSE, Korean version of Mini-Mental Status Examination; K-MBI, Korean version of Modified Barthel Index; VFSS, videofluoroscopic swallowing study.
Table 2. Characteristics of dysphagia measured by VDS using VFSS in aSAH

\begin{tabular}{|c|c|c|c|}
\hline Characteristic & $\begin{array}{c}\text { Low risk } \\
(\mathrm{n}=47)\end{array}$ & $\begin{array}{c}\text { High risk } \\
(\mathrm{n}=17)\end{array}$ & p-value \\
\hline \multicolumn{4}{|l|}{ Lip closure } \\
\hline Intact & $41(87.2)$ & $7(41.2)$ & 0.415 \\
\hline Inadequate & $5(10.6)$ & $7(41.2)$ & \\
\hline None & $1(2.1)$ & $3(17.6)$ & \\
\hline \multicolumn{4}{|l|}{ Bolus formation } \\
\hline Intact & $27(57.4)$ & $7(41.2)$ & 0.297 \\
\hline Inadequate & $19(40.4)$ & $5(29.4)$ & \\
\hline None & $1(2.1)$ & $5(29.4)$ & \\
\hline \multicolumn{4}{|l|}{ Mastication } \\
\hline Intact & $31(66.0)$ & $5(29.4)$ & 0.957 \\
\hline Inadequate & $15(31.9)$ & $7(41.2)$ & \\
\hline None & $1(2.1)$ & $5(29.4)$ & \\
\hline \multicolumn{4}{|l|}{ Apraxia } \\
\hline None & $21(44.7)$ & $1(5.9)$ & 0.499 \\
\hline Mild & $10(21.3)$ & $2(11.8)$ & \\
\hline Moderate & $15(31.9)$ & $8(47.1)$ & \\
\hline Severe & $1(2.1)$ & $6(35.3)$ & \\
\hline \multicolumn{4}{|c|}{ Tongue to palate contact } \\
\hline Intact & $32(68.1)$ & $2(11.8)$ & 0.519 \\
\hline Inadequate & $14(29.8)$ & $10(58.8)$ & \\
\hline None & $1(2.1)$ & $5(29.4)$ & \\
\hline \multicolumn{4}{|c|}{ Premature bolus loss (\%) } \\
\hline None & $29(61.7)$ & $1(5.9)$ & 0.104 \\
\hline$<10$ & $10(21.3)$ & $5(29.4)$ & \\
\hline $10-50$ & $6(12.8)$ & $6(35.3)$ & \\
\hline$>50$ & $2(4.3)$ & $5(29.4)$ & \\
\hline \multicolumn{4}{|l|}{ Oral transit time (s) } \\
\hline$<1.5$ & $30(63.8)$ & $4(23.5)$ & 0.157 \\
\hline$>1.5$ & $17(36.2)$ & $13(76.5)$ & \\
\hline \multicolumn{4}{|c|}{ Triggering of pharyngeal swallow } \\
\hline Normal & $35(74.5)$ & $5(29.4)$ & 0.157 \\
\hline Delayed & $12(25.5)$ & $12(70.6)$ & \\
\hline \multicolumn{4}{|c|}{ Vallecular residue (\%) } \\
\hline None & $26(55.3)$ & $2(11.8)$ & 0.113 \\
\hline$<10$ & $12(25.5)$ & $3(17.6)$ & \\
\hline $10-50$ & $6(12.8)$ & $6(35.3)$ & \\
\hline$>50$ & $3(6.4)$ & $6(35.3)$ & \\
\hline
\end{tabular}


Table 2. Continued

\begin{tabular}{|c|c|c|c|}
\hline Characteristic & $\begin{array}{c}\text { Low risk } \\
(n=47)\end{array}$ & $\begin{array}{c}\text { High risk } \\
(n=17)\end{array}$ & p-value \\
\hline \multicolumn{4}{|l|}{ Laryngeal elevation } \\
\hline Normal & $39(83.0)$ & $5(29.4)$ & 0.157 \\
\hline Impaired & $8(17.0)$ & $12(70.6)$ & \\
\hline \multicolumn{4}{|c|}{ Pyriform sinus residue (\%) } \\
\hline None & $27(57.4)$ & $1(5.9)$ & 0.138 \\
\hline$<10$ & $15(31.9)$ & $3(17.6)$ & \\
\hline $10-50$ & $4(8.5)$ & $8(47.1)$ & \\
\hline$>50$ & $1(2.1)$ & $5(29.4)$ & \\
\hline \multicolumn{4}{|c|}{ Coating on the pharyngeal wall } \\
\hline No & $38(80.9)$ & $6(35.3)$ & 0.157 \\
\hline Yes & $9(19.1)$ & $11(64.7)$ & \\
\hline \multicolumn{4}{|c|}{ Pharyngeal transit time (s) } \\
\hline$<1.0$ & $33(70.2)$ & $6(35.3)$ & 0.157 \\
\hline$>1.0$ & $14(29.8)$ & $11(64.7)$ & \\
\hline \multicolumn{4}{|l|}{ Aspiration } \\
\hline None & $32(68.1)$ & $2(11.8)$ & 0.240 \\
\hline Penetration & $11(23.4)$ & $4(23.5)$ & \\
\hline Aspiration & $4(8.5)$ & $11(64.7)$ & \\
\hline Mean VDS score & $20.6 \pm 19.4$ & $63.6 \pm 16.1$ & \\
\hline
\end{tabular}

Values are presented as number (\%).

VDS, videofluoroscopic dysphagia scale; VFSS, videofluoroscopic swallowing study; aSAH, aneurysmal subarachnoid hemorrhage.

Table 3 displays univariate analysis results. The number of patients assigned to the high-risk group (VDS $>47$ ) was 17 (26.6\%), and the low-risk group 47 (73.4\%). The onset age, initial GCS score, Hijdra score, the presence of IVH, K-MMSE, and K-MBI differed significantly between the two subsamples.

All significant parameters were adjusted in the multivariate analysis as shown in Table 4 . The parametersinitial GCS score $(p=0.048)$, Hijdra score $(p=0.028)$, the presence of IVH $(p=0.038)$, and K-MMSE $(p=0.007)$-at the time of VFSS were independently predisposing for dysphagia over 6 months after stroke onset in patients with aSAH.

\section{DISCUSSION}

To the best of our knowledge, this study is the first report that investigated the characteristics of dysphagia and risk factors over 6 months after stroke onset in patients
Table 3. Univariate analysis for identification of parameters which were associated with dysphagia over 6 months after stroke onset in patients with aSAH

\begin{tabular}{|c|c|c|c|}
\hline Parameter & $\begin{array}{c}\text { Low risk } \\
(\mathrm{n}=47)\end{array}$ & $\begin{array}{c}\text { High risk } \\
(\mathrm{n}=17)\end{array}$ & p-value \\
\hline Age (yr) & $52.6 \pm 11.8$ & $59.6 \pm 16.3$ & $0.043^{*}$ \\
\hline Sex & & & 0.825 \\
\hline Male & $29(61.7)$ & $10(58.8)$ & \\
\hline Female & $18(38.3)$ & $7(41.2)$ & \\
\hline Hypertension & $36(76.6)$ & $12(70.6)$ & 0.720 \\
\hline DM & $9(19.1)$ & $4(23.5)$ & 0.793 \\
\hline Initial GCS & $11.1 \pm 4.1$ & $7.8 \pm 3.8$ & $0.004^{*}$ \\
\hline Endotracheal tube & $2(4.3)$ & $4(23.5)$ & $0.016^{*}$ \\
\hline Treatment modality & & & 0.157 \\
\hline Clipping & $39(83.0)$ & 15 (88.2) & \\
\hline Coiling & $6(12.8)$ & $2(11.8)$ & \\
\hline Conservative & $2(4.3)$ & $0(0)$ & \\
\hline Hunt and Hess scale & & & 0.068 \\
\hline Grade 1 & $0(0)$ & $0(0)$ & \\
\hline Grade 2 & $9(19.1)$ & $2(11.8)$ & \\
\hline Grade 3 & $10(21.3)$ & $3(17.6)$ & \\
\hline Grade 4 & $28(59.6)$ & $9(52.9)$ & \\
\hline Grade 5 & $0(0)$ & $3(17.6)$ & \\
\hline Hijdra score & $16.8 \pm 8.4$ & $22.7 \pm 7.1$ & $0.019^{*}$ \\
\hline IVH & $16(34.0)$ & $13(76.5)$ & $0.001^{*}$ \\
\hline Aneurysmal location & & & 0.094 \\
\hline A-com & $14(29.8)$ & $4(23.6)$ & \\
\hline P-com & $10(21.3)$ & $3(17.7)$ & \\
\hline MCA & $9(19.2)$ & $4(23.6)$ & \\
\hline Pericallosal & $5(10.7)$ & $3(17.5)$ & \\
\hline ICA bifurcation & $4(8.6)$ & $1(5.9)$ & \\
\hline Basilar tip & $3(6.4)$ & $0(0)$ & \\
\hline Others & $2(4.3)$ & $2(11.8)$ & \\
\hline K-MMSE & $16.2 \pm 10.9$ & $6.4 \pm 4.2$ & $0.001^{*}$ \\
\hline K-MBI & $33.4 \pm 19.5$ & $18.9 \pm 11.3$ & $0.047^{*}$ \\
\hline
\end{tabular}

Values are presented as mean \pm standard deviation or number (\%).

aSAH, aneurysmal subarachnoid hemorrhage; DM, diabetes mellitus; GCS, Glasgow Coma Scale; IVH, intraventricular hemorrhage; A-com, anterior communicating artery; P-com, posterior communicating artery; MCA, middle cerebral artery; ICA, internal carotid artery; KMMSE, Korean version of Mini-Mental Status Examination; K-MBI, Korean version of Modified Barthel Index. ${ }^{*} \mathrm{p}<0.05$. 
Table 4. Multivariate logistic regression model for prediction of high risk for dysphagia over 6 months after stroke onset in patients with aSAH

\begin{tabular}{lccc}
\hline & OR & $\mathbf{9 5 \%}$ CI & p-value \\
\hline Age & 1.052 & $0.936-1.183$ & 0.393 \\
Initial GCS & 0.943 & $0.814-1.057$ & $0.048^{*}$ \\
Hijdra score & 1.100 & $0.984-1.395$ & $0.028^{*}$ \\
Presence of IVH & 1.225 & $0.992-1.449$ & $0.038^{*}$ \\
K-MMSE & 1.864 & $1.541-2.046$ & $0.007^{*}$ \\
K-MBI & 1.131 & $0.901-1.419$ & 0.290 \\
\hline
\end{tabular}

aSAH, aneurysmal subarachnoid hemorrhage; OR, odds ratio; CI, confidence interval; GCS, Glasgow Coma Scale; $\mathrm{IVH}$, intraventricular hemorrhage; Korean version of Mini-Mental Status Examination; K-MBI, Korean version of Modified Barthel Index.

${ }^{*} \mathrm{p}<0.05$.

with aSAH by using both objective and quantification tools.

We found that more than $50 \%$ of patients demonstrated both oral and pharyngeal phase abnormalities and the incidence rate of those expected to have swallowing difficulties over 6 months after stroke onset was $26.5 \%(n=17)$. The frequency of oral phase abnormalities including bolus formation, mastication, apraxia, tongue-palate contact, and premature bolus loss was more common than in other stroke types. A recent study that investigated the characteristics of dysphagia in a cerebral infarct using a VFSS and fiberoptic endoscopic evaluation of swallowing (FEES) reported $25 \%$ of the patients showing oral phase abnormalities with prolonged oral transit time, while 83.4\% were diagnosed with pharyngeal phase dysphagia [14]. Another investigation on dysphagia in ischemic strokes less than 3 months after onset using VFSS also revealed similar results [15]. In addition, the research that reported on dysphagia in patients with acute striatocapsular hemorrhage evaluated by FEES demonstrated oral phase abnormalities in $3 \%$ of the subjects, although $93 \%$ of them showed pharyngeal phase abnormalities including liquid penetration or aspiration [16].

In this study, the dysphagia risk factors over 6 months after stroke onset in aSAH were the initial GCS score, hemorrhage volume, IVH, and cognitive deficits. These risk factors were similar to risk factors for dysphagia in patients with some degree of a stroke. Age $[17,18]$, black race [18], initial GCS score [18], ICH volume $[18,19]$ and
Functional Independence Measure (FIM) scores on admission [17] were known to be independent predictors for long-term dysphagia in patients with hemorrhagic stroke. In comparison, the NIHSS score [20,21], age [2022], left-sided lesion [23], history of diabetes [22], and baseline functional independence [21] were risk factors for dysphagia in ischemic stroke. The GCS is the one of the important prognostic factors for functional recovery in aSAH [24]: the poor neurological status at the onset as captured by the GCS and NIHSS affected the prognosis of dysphagia in both ischemic and hemorrhagic strokes as a result.

The amount of hemorrhage measured by the Hijdra score was also a predictor for dysphagia over 6 months after stroke onset in aSAH. Additionally, the occurrence of a cerebral vasospasm that greatly interrupts functional recovery is associated with the amount of hemorrhage in aSAH [25]. The presence of an ICH with aSAH is a wellknown risk factor for a poor neurologic outcome [26]; although patients who showed a co-existing ICH were excluded to rule out this influence, the amount of hemorrhage itself was an independent predictor for dysphagia after stroke onset with ICH.

IVH was the one of the risk factors that influenced the dysphagia prognosis with aSAH, but the corresponding mechanism is as of yet not well known. However, clotted blood in the ventricles increases the pressure and causes direct damage to the brain cells lining the periventricular white matter (PVWM) which plays a role in swallowing. In this respect, Cola et al. [27] reported that patients with a subcortical stroke involving the left PVWM frequently showed dysphagia with oral phase abnormalities. Moreover, IVH itself affected dysphagia indirectly by inducing consciousness impairment [28].

The K-MMSE was also a predictor for dysphagia. The association of cognitive dysfunction regarding the degree and prognosis of dysphagia with a stroke is well known [29-31]. In addition, the relationship between cognitive deficits and dysphagia is significant in other central nervous system diseases such as dementia, mild cognitive impairment (MCI), and Parkinson disease. Because cognitive impairment across multiple domains is common in patients with aSAH as mentioned above, we confirmed that cognitive function recovery is essential for improving the swallowing function. Therefore, we recommend a cognitive function evaluation using the K-MMSE or 
the Montreal Cognitive Assessment (MOCA) to detect impairment in patients with aSAH. If impairment is confirmed, appropriate cognitive rehabilitation may contribute to improvement in dysphagic patients with aSAH $[32,33]$.

Age and K-MBI, the latter reflecting functional dependency, were not included in the final model after multivariate analysis. Regarding the first, a few old patients were enrolled in this study, because researchers who investigated the prognosis of dysphagia with a stroke and aSAH suggested that an age of over 70 years is a predictor for poor outcomes [34]. The K-MBI was excluded as well, because the majority of patients with aSAH elicited some degree of confusion or arousal abnormalities in the subacute period [2].

Limitations of this study included the following: first, it was based on research by Han et al. [9], which reported valid and reliable evaluations of post-stroke dysphagia for over 6 months. A study which investigated aspiration pneumonia caused by dysphagia in patients (including $\mathrm{SAH})$ with post-stroke dysphagia including patients reported VFSS results as the most important predictor of dysphagia severity [35]. Nonetheless, because this study did not directly predict dysphagia characteristics and its risk factors in patients with aSAH for over 6 months, scope of applicable, valid interpretations is narrow. And although this study analyzed the characteristics and risk factors of dysphagia in patients with SAH for over 6 months based on a reference, no previous study provide reference for analysis of the two research objectives. Also, there are potential confounding factor: complications including delayed cerebral ischemia (DCI) [36], hydrocephalus [37] and recurrent bleeding [38] may also affect the outcomes of dysphagia in patients with aSAH. The incidence rate of DCI among the SAH patients is about $20 \%$ [36] and that of hydrocephalus is about $10 \%$ [37], which can affect dysphagia. The recurrence rate of SAH is about $1 \%-4 \%$ within 1 year [38] and it might have had minor, partial influence. The same applies to other types of stroke recurrence like ICH or cerebral infarction which can occur during the same timeframe. Other than that, aspiration pneumonia, possibly occurring in the low-risk group, might have prolonged the duration of dysphagia, and whether the patients took swallowing rehabilitation or not can influence the result considerably. Second, the sample size was small; since this was a retrospective study in a single center, there might have been a selection bias. Third, the incidence of dysphagia with aSAH was not investigated in detail. In fact, it varies up to five-fold, according to the method of defining and diagnosing dysphagia [3]. The rate of patients who expected dysphagia over 6 months was $26.6 \%(n=17)$ in this study, whereas the proportion of those with VFSS abnormalities was $85.9 \%(n=55)$. However, not every patient who presented abnormal findings during the subacute period after aSAH needed comprehensive swallowing rehabilitation. Thus, we focused on the analysis of the high-risk group who needed treatment and other interventions for dysphagia. Fourth, alternative common causes of dysphagia with oral phase abnormalities were not investigated in types of stroke other than aSAH. Such limitations should be compensated by future large-scale multi-center studies.

In conclusion, oral phase abnormalities were more prominent in patients with aSAH than in those with other types of stroke. The risk factors for dysphagia persisting over 6 months after stroke onset were the initial GCS, hemorrhage volume, presence of IVH, and cognition as measured by the K-MMSE.

\section{CONFLICT OF INTEREST}

No potential conflict of interest relevant to this article was reported.

\section{ACKNOWLEDGMENTS}

This work was supported by the Wonkwang Institute of Clinical Medicine in 2016.

\section{REFERENCES}

1. Feigin VL, Lawes CM, Bennett DA, Barker-Collo SL, Parag V. Worldwide stroke incidence and early case fatality reported in 56 population-based studies: a systematic review. Lancet Neurol 2009;8:355-69.

2. Connolly ES Jr, Rabinstein AA, Carhuapoma JR, Derdeyn CP, Dion J, Higashida RT, et al. Guidelines for the management of aneurysmal subarachnoid hemorrhage: a guideline for healthcare professionals from the American Heart Association/American Stroke Association. Stroke 2012;43:1711-37.

3. Martino R, Foley N, Bhogal S, Diamant N, Speech- 
ley M, Teasell R. Dysphagia after stroke: incidence, diagnosis, and pulmonary complications. Stroke 2005;36:2756-63.

4. Nii M, Maeda K, Wakabayashi H, Nishioka S, Tanaka A. Nutritional improvement and energy intake are associated with functional recovery in patients after cerebrovascular disorders. J Stroke Cerebrovasc Dis 2016;25:57-62.

5. Rabadi MH, Coar PL, Lukin M, Lesser M, Blass JP. Intensive nutritional supplements can improve outcomes in stroke rehabilitation. Neurology 2008; 71:1856-61.

6. Perry L, Love CP. Screening for dysphagia and aspiration in acute stroke: a systematic review. Dysphagia 2001;16:7-18.

7. Yap EC, Chua KS. Rehabilitation outcome after primary subarachnoid haemorrhage. Brain Inj 2002;16:491-9.

8. Logemann JA, Veis S, Colangelo L. A screening procedure for oropharyngeal dysphagia. Dysphagia 1999; 14:44-51.

9. Han TR, Paik NJ, Park JW, Kwon BS. The prediction of persistent dysphagia beyond six months after stroke. Dysphagia 2008;23:59-64.

10. Kim J, Oh BM, Kim JY, Lee GJ, Lee SA, Han TR. Validation of the videofluoroscopic dysphagia scale in various etiologies. Dysphagia 2014;29:438-43.

11. Kim DH, Choi KH, Kim HM, Koo JH, Kim BR, Kim TW, et al. Inter-rater reliability of videofluoroscopic dysphagia scale. Ann Rehabil Med 2012;36:791-6.

12. Daniels SK. Swallowing apraxia: a disorder of the Praxis system? Dysphagia 2000;15:159-66.

13. Hijdra A, Brouwers PJ, Vermeulen M, van Gijn J. Grading the amount of blood on computed tomograms after subarachnoid hemorrhage. Stroke 1990;21:1156-61.

14. Wan P, Chen X, Zhu L, Xu S, Huang L, Li X, et al. Dysphagia post subcortical and supratentorial stroke. J Stroke Cerebrovasc Dis 2016;25:74-82.

15. Kim SY, Kim TU, Hyun JK, Lee SJ. Differences in videofluoroscopic swallowing study (VFSS) findings according to the vascular territory involved in stroke. Dysphagia 2014;29:444-9.

16. Suntrup S, Warnecke T, Kemmling A, Teismann IK, Hamacher C, Oelenberg S, et al. Dysphagia in patients with acute striatocapsular hemorrhage. J Neurol 2012; 259:93-9.

17. Maeshima S, Okazaki H, Okamoto S, Mizuno S, Asano
$\mathrm{N}$, Tsunoda $\mathrm{T}$, et al. Dysphagia following putaminal hemorrhage at a rehabilitation hospital. J Stroke Cerebrovasc Dis 2016;25:389-96.

18. Faigle R, Marsh EB, Llinas RH, Urrutia VC, Gottesman RF. Novel score predicting gastrostomy tube placement in intracerebral hemorrhage. Stroke 2015;46:316.

19. Maeshima S, Osawa A, Yamane F, Ishihara S, Tanahashi N. Dysphagia following acute thalamic haemorrhage: clinical correlates and outcomes. Eur Neurol 2014;71:165-72.

20. Ribeiro PW, Cola PC, Gatto AR, da Silva RG, Luvizutto GJ, Braga GP, et al. Relationship between dysphagia, national institutes of health stroke scale score, and predictors of pneumonia after ischemic stroke. J Stroke Cerebrovasc Dis 2015;24:2088-94.

21. Nakajima M, Inatomi Y, Yonehara T, Hashimoto Y, Hirano $\mathrm{T}$. Acquisition of oral intake in severely dysphagic patients with acute stroke: a single-center, observational study involving a database of 4972 consecutive stroke patients. J Neurol Sci 2012;323:56-60.

22. Hamidon BB, Nabil I, Raymond AA. Risk factors and outcome of dysphagia after an acute ischaemic stroke. Med J Malaysia 2006;61:553-7.

23. Yamamoto K, Koh H, Shimada H, Takeuchi J, Yamakawa $\mathrm{Y}$, Kawamura M, et al. Cerebral infarction in the left hemisphere compared with the right hemisphere increases the risk of aspiration pneumonia. Osaka City Med J 2014;60:81-6.

24. van Heuven AW, Dorhout Mees SM, Algra A, Rinkel GJ. Validation of a prognostic subarachnoid hemorrhage grading scale derived directly from the Glasgow Coma Scale. Stroke 2008;39:1347-8.

25. Dupont SA, Wijdicks EF, Manno EM, Lanzino G, Rabinstein AA. Prediction of angiographic vasospasm after aneurysmal subarachnoid hemorrhage: value of the Hijdra sum scoring system. Neurocrit Care 2009;11:172-6.

26. Wan A, Jaja BN, Schweizer TA, Macdonald RL. Clinical characteristics and outcome of aneurysmal subarachnoid hemorrhage with intracerebral hematoma. J Neurosurg 2016:1-8.

27. Cola MG, Daniels SK, Corey DM, Lemen LC, Romero M, Foundas AL. Relevance of subcortical stroke in dysphagia. Stroke 2010;41:482-6.

28. Passero S, Ulivelli M, Reale F. Primary intraven- 
tricular haemorrhage in adults. Acta Neurol Scand 2002;105:115-9.

29. Moon HI, Pyun SB, Kwon HK. Correlation between location of brain lesion and cognitive function and findings of videofluoroscopic swallowing study. Ann Rehabil Med 2012;36:347-55.

30. Toscano M, Cecconi E, Capiluppi E, Vigano A, Bertora $\mathrm{P}$, Campiglio L, et al. Neuroanatomical, clinical and cognitive correlates of post-stroke dysphagia. Eur Neurol 2015;74:171-7.

31. Falsetti P, Acciai C, Palilla R, Bosi M, Carpinteri F, Zingarelli A, et al. Oropharyngeal dysphagia after stroke: incidence, diagnosis, and clinical predictors in patients admitted to a neurorehabilitation unit. J Stroke Cerebrovasc Dis 2009;18:329-35.

32. Loetscher T, Lincoln NB. Cognitive rehabilitation for attention deficits following stroke. Cochrane Database Syst Rev 2013;(5):CD002842.

33. Chung CS, Pollock A, Campbell T, Durward BR, Hagen S. Cognitive rehabilitation for executive dysfunction in adults with stroke or other adult non-progressive acquired brain damage. Cochrane Database Syst Rev 2013;(4):CD008391.

34. Chua MH, Griessenauer CJ, Thomas AJ, Ogilvy CS.
Who is likely to present in poor neurological condition after aneurysmal subarachnoid hemorrhage? Risk factors and Implications for Treatment. World Neurosurg 2016;92:113-9.

35. Lakshminarayan K, Tsai AW, Tong X, Vazquez G, Peacock JM, George MG, et al. Utility of dysphagia screening results in predicting poststroke pneumonia. Stroke 2010;41:2849-54.

36. Frontera JA, Fernandez A, Schmidt JM, Claassen J, Wartenberg KE, Badjatia N, et al. Defining vasospasm after subarachnoid hemorrhage: what is the most clinically relevant definition? Stroke 2009;40:1963-8.

37. Kwon JH, Sung SK, Song YJ, Choi HJ, Huh JT, Kim HD. Predisposing factors related to shunt-dependent chronic hydrocephalus after aneurysmal subarachnoid hemorrhage. J Korean Neurosurg Soc 2008;43: 177-81.

38. Bederson JB, Connolly ES Jr, Batjer HH, Dacey RG, Dion JE, Diringer MN, et al. Guidelines for the management of aneurysmal subarachnoid hemorrhage: a statement for healthcare professionals from a special writing group of the Stroke Council, American Heart Association. Stroke 2009;40:994-1025. 